\title{
Sıcaklık Stresi Oluşturulan Broilerde Yeme İlave Edilen Hypericum scabrum L. (Mayasıl Otu) ve Taraxacum officinale L. (Karahindiba) Bitki Ekstraktlarının Performans Değerleri ile Karaciğer ve Bağırsak Ağırlığı Üzerine Etkileri
}

\begin{tabular}{l|c}
\hline $\begin{array}{l}\text { Araştırma / Research } \\
\text { Geliş Tarihi / Received } \\
04.07 .2017\end{array}$ & Muhammet Ali TUNÇ \\
Kabul Tarih / Accepted & \\
20.02 .2018 & Atatürk Üniversitesi Narman Meslek Yüksekokulu, Veteriner Bölümü, \\
DOI & Erzurum/Turkey \\
10.28955/alinterizbd.325919 & e-posta: matunc@atauni.edu.tr \\
ISSN 2564-7814 & \\
e-ISSN 2587-2249 & \\
\hline
\end{tabular}

Öz: Bu araştırma da, normal şartlar da ve 1sı stresi altında yetiştirilen broilerlerin rasyonlarına Taraxacum officinale L. ve Hypericum scabrum L. ekstraktı katkısının Karaciğer+Bağırsak ağırlığ ile canlı ağırlık ve yemden yararlanma oranı üzerine etkilerinin belirlenmesi amaçlanmıştır. Araştırmada kullanılan Taraxacum officinale L. ve Hypericum scabrum $L$. bitkileri Erzurum ilinden toplanarak uygun șartlarda eksrakte edilerek yemlere ilave edildi. Hayvan materyali olarak 96 adet Ross 308 erkek broiler civciv kullanılmıştır. Broiler civcivler rastgele seçilerek her grupta 16 civciv olacak şekilde, 4 tekerrürlü 6 gruba ayrıldı. Grupların 3'ü normal şartlarda bakılırken, 3 gruba da deneme periyodunun sadece 15-30. günleri arasında $38-39^{\circ} \mathrm{c}$ 'de sıcaklık stresi (S) uyguland1. Birinci deneme grubun daki hayvanlar, herhangi bir katkı ilave edilmeyen (Bazal) yemle beslenerek kontrol (Grup K) grubu oluşturuldu. İkinci deneme grubun daki hayvanlara \%0,1 oranında $T$. officinale $L$. ekstraktı katkılı yem verildi (Grup T). Üçüncü deneme grubun daki hayvanlara \%0,1 oranında $H$. scrabum L. ekstraktı katk1lı yem verildi (Grup H). Dördüncü deneme grubun daki hayvanlara sıcaklık stresi uygulanarak katkısız yem verildi (Grup $\mathrm{K}+\mathrm{S})$. Beşinci deneme grubun daki hayvanlara sıcaklık stresi uygulanarak \% 0,1 oranında $T$. officinale $L$. ekstraktı katkılı yem verildi (Grup $\mathrm{T}+\mathrm{S})$. Altıncı deneme grubun daki hayvanlara sıcaklık stresi uygulanarak \% 0,1 oranında $H$. scabrum $L$. ekstraktı katkılı yem verildi (Grup $\mathrm{H}+\mathrm{S}$ ). Çalışma 45 gün sürdü. Deneme sonu canlı ağırlıklarında Grup K, Grup T ve Grup H’ nin değerleri benzer olurken, Grup K ile sıcaklık stresi uygulanan tüm gruplarla arasındaki fark önemli olmuştur $(p<0.05)$. karaciğer ve Bağırsak ağırlıklarında da Grup K ve Grup T ile sıcaklık stresi uygulanan tüm gruplar arasındaki fark önemli olmuştur (p< 0.05). Sonuç olarak, broiler yemine katılan H. scrabum L. ve T. officinale L. ekstraktının 1sı stresinin olumsuz etkileri üzerine herhangi bir olumlu etkisi olmamıştır.

Anahtar Kelimeler: Broiler, ekstrakt, Hypericum scabrum L., yem katkıs1, Taraxacum officinale L.

\section{Effects on Performance Values with Liver and Intestinal Weight of Taraxacum officinale L. and Hypericum scabrum L. Plant Extracts Feed Added to Heat Stress Broilers}

\begin{abstract}
In this study, it was aimed that determine the effects of on liver + gut weight, total body weight and feed conversion ratio Taraxacum officinale L. and Hypericum scabrum L. extract add ratio broiler rations under normal conditions and heat stress. Taraxacum officinale L. and Hypericum scabrum L. plants used in the research were collected from Erzurum province that added to feed by being extract under suitable conditions. As animal material were used 96 pieces of Ross 308 male broiler chicks. Broiler chicks were randomly selected and divided into 6 groups of 4 repetitions, with 16 chicks in each group. While 3 groups were examined under normal conditions, 3 groups were subjected to temperature stress (S) at 38-390c between only 15-30 days of the test period. The animals in the first trial group was formed Control group (Group K) by feeding with no added (Basal) feed. The animals in the second experimental group was fed $0.1 \%$ T. officinale L. extract (Group T). The animals in the third experimental group was added to $0.1 \%$ of $H$. scrabum $L$. extract (Group $\mathrm{H}$ ). The animals in the fourth experimental group was given unadulterated feed by applying heat stress (Group $\mathrm{K}+\mathrm{S}$ ). The animals in the fifth experiment group was applied temperature stress to and $T$. officinale $L$. extract feed added (Group $\mathrm{T}+\mathrm{S}$ ). The animals in the sixth experiment group was applied temperature stress to and $0.1 \%$ H. scabrum L. extract feed added (Group H $+\mathrm{S}$ ). Work lasted 45 days. While total body weight similar values of Group K, Group T and Group H, group K was significant difference between all groups to which the heat stress was applied $(p<0.05)$. Liver and intestinal weights were significantly different between Group K and Group T and all groups to which heat stress was applied ( $\mathrm{p}<0.05)$. As a result, H. scrabum L. and $T$. officinale $L$. extract, which were added to the broiler diet, had no positive effect on the negative effects of heat stress.
\end{abstract}

Keywords: Broiler, extract, Hypericum scabrum L., feed additive, Taraxacum officinale L.

Lütfen aşağıdaki şekilde atıf yapınız / Please cite this paper as follows:

Tunç, M.A., 2018. Sıcaklık Stresi Oluşturulan Broilerde Yeme İlave Edilen Hypericum scabrum L. (Mayasıl otu) ve Taraxacum officinale L. (Karahindiba) Bitki Ekstraktlarının Performans Değerleri ile Karaciğer ve Bağırsak Ağırlığı Üzerine Etkileri. Alınteri Journal of Agriculture Sciences, 33(1): 1-6 


\section{GíRIŞ}

Stres, canlı organizmada birçok fonksiyonu etkileyerek verim, canlı ağırlık kazancı ve yem tüketiminde azalma gibi istenmeyen etkilere sebep olduğu (Puvadolpirod and Thaxton, 2000; Çınar ve ark., 2006; Dönmez ve ark., 2007) gibi hayvanların bağışıklık düzeyinin düşmesine ve çevresel faktörlerin zararlı etkilerinin hayvanlar üzerinde daha etkili olmasına ayrıca bir çok biyokimyasal parametrenin değişmesinde önemli bir etken olmuştur (Daneshyar et al., 2009). Kanatlı hayvanları strese sokan şartlar içinde en önemlisi sıcaklık stresidir (Alarslan, 2000). Sicaklık stresi kanatlılarda canlı ağırlığı, yem tüketimini ve yemden yararlanma oranında düşüşle ilişkilendirilmiştir (Donkoh, 1989). Kanatlllarda 1Sı stresinin sebep olduğu bu zararlı etkileri azaltmak için vitamin (Çiftçi, 2005), mineral (Şahin, 2005) ve bitki yağları (Karsl1, 2007) gibi birçok doğal madde yem katkısı olarak kullanılmıştır. Yem katkısı olarak kullanılması düşünülen doğal bitkilerden biri de, Hypericum cinsine ait Hypericum scabrum L. olmuştur. Bu tür Anadolu da "mayasıl otu, kepirotu" olarakta isimlendirilir (Kurbanov ve Mutayev, 1993; Baytop, 1997). Bu bitki türleri fenol içeriğine sahip oldukları gibi antioksidan özelliğe ve besinsel değere sahiptirler. (Christie, 1994; Keskin, 2015). Ayrıca Hypericum scabrum L. 'un antimikrobiyel, antiseptik, antihelmintik, antifungal ve ishal önleyici özelliğe sahip olduğu da tespit edilmiştir (Unal, 2008; Ebrahimzadeh, 2013; Pirbalouti 2014). Bu doğrultuda kullanılan diğer bir bitki de Taraxacum officinale'dir. Bu bitki çayırlarda ve yol kenarlarında yetişebilen çok yıllık, sarı renkte çiçekleri olan, Papatyagiller (Asteraceae) familyasının bir üyesidir. Aynı zamanda Karahindiba olarak ta bilinir (Davis, 1965; Koç, 2002). Taraxacum officinale laksatif, diüretik, anti-diabetik ( Önal et al., 2005; Ertaş et al., 2005) ve kan temizleyici olarak ta kullanılmıştır. (Bisset et al., 1994). Ayrıca yapılan diğer çalışmalarda Taraxacum officinale'nın anti-inflamator (Kim et al., 2000), antibakteriyel (Amin Mir, 2016), anti-oxidatif (Hu and Kitts, 2005), anti-alerjik (Ho et al., 1998), anti-koagulan (Yun et al., 2002) aktiviteye sahip olduğu bildirilmiştir. Bu bitkilerin sahip oldukları bu özelliklerden dolayı doğal yem katkısı olarak kullanılmaları düşünülmüştür.

$\mathrm{Bu}$ çalışma da, hem normal şartlar da, hem de yaşamlarının belli bir döneminde (15-30. gün arası) sıcaklık stresi uygulanan broiler rasyonlarına Taraxacum officinale L. ve Hypericum scabrum L. bitki ekstraktı katkısının baş, karaciğer ve bağırsak ağırlığı ile canlı ağırlık ve yemden yararlanma oranı üzerine etkilerinin belirlenmesi amaçlanmıştır.

\section{MATERYAL VE YÖNTEM}

Araştırmada kullanılan Taraxacum officinale L. ve Hypericum scabrum L. bitkileri Erzurum ilinde Haziran ayında toplanarak gölgede kurutulup öğütüldü. Öğ̈̈tülen bitkilerden 100'er gr alınarak 1000 ml'lik balonlara konulup, balonlara ayrı ayrı 500’er ml etanol ilave edildi. 48 saat sonunda bitki materyalleri ve organik çözücüler ince bir tülbentten süzülüp bitki materyalleri süspansiyondan ayrıldı. Toplanan karışımdan organik çözücüler rotary evaporatör yardımıyla uzaklaştırılarak ekstraktlar elde edildi. Elde edilen eksraktlar çalışmada kullanılmak üzere $+4^{\circ} \mathrm{C}$ 'deki buzdolabinda muhafaza edildi.

Araştırma Atatürk Üniversitesi Yerel Etik Kurulu onayı (23.07.2013 tarih ve 36643897-652 sayılı yazı ile gereken etik kurul belgesi) alındıktan sonra Atatürk Üniversitesi Veteriner Fakültesi Hayvancılık Araştırma ve Uygulama Birimi Kanatlı ünitesinde yürütüldü. Çalışma da 1 günlük yaşta 96 tane Ross 308 erkek broiler civciv kullanıldı. Hayvanlar rastgele seçilerek her grupta 16 civciv olacak şekilde 4'er hayvanlı 4 tekerrürlü 6 gruba ayrıldı. Grupların 3'ne normal sıcaklık şartlarında bakılırken, diğer 3 gruba da deneme periyodunun sadece 15-30. günleri arasında 38-39 c'de sicaklık stresi (S) uygulandı. Deneme gruplarındaki hayvanlardan, birinci deneme grubun da ki hayvanlara, herhangi bir katkı ilave edilmeyen (Bazal) yemle beslenerek kontrol (Grup K) grubu oluşturuldu. İkinci deneme grubun da ki hayvanlara \% 0,1 oranında $T$. officinale L. ekstraktı katkılı yem verildi (Grup T). Üçüncü deneme grubun da ki hayvanlara \% 0,1 oranında $H$. scrabum L. ekstraktı katkılı yem verildi (Grup $H)$. Dördüncü deneme grubun da ki hayvanlara sıcaklık stresi uygulanarak katkısız yem verildi $(\mathrm{K}+\mathrm{S})$. Beşinci deneme grubun da ki hayvanlara sicaklık stresi uygulanarak \% 0,1 oranında $T$. officinale $L$. ekstraktı katkılı yem verildi (Grup T+S). Altıncı deneme grubun da ki hayvanlara sicaklık stresi uygulanarak \% 0,1 oranında H. scabrum L. ekstraktı katkılı yem verildi (Grup H+S). Hayvanlar rakamlı ayak klipsleri ile bireysel olarak numaralandırıldılar. Çalışmadaki hayvan (bireysel olarak) ve yem tartımları haftalık olarak yapıldı. Hayvanlara yem ve su ad libitum olarak verildi. Çalışma 45 gün sürdü. Bitki ekstraktı ilave edilen yemler hayvanlara 8. günden itibaren verildi. Karma yem haftalık olarak hazırlandı. Araştırmada; İçeriği ve kimyasal kompozisyonu Çizelge 1' de verilen karma yemler kullanıldı. 
Alınteri Journal of Agriculture Sciences. 2018, 33(1): 1-6

Alınteri Zirai Bilimler Dergisi

Çizelge 1. Kullanılan karma yemin bileşimi (\%).

\begin{tabular}{|c|c|c|c|c|}
\hline Yem Maddeleri & 7-14. gün & 14-21.gün & 21-28.gün & >28.gün \\
\hline Misır, \% & 36,72 & 37,67 & 36,61 & 33,89 \\
\hline Yağlı soya, \% & 27,50 & 21,07 & 19,13 & 20,07 \\
\hline Kuru soya, \% & 12,69 & 15,00 & 17,50 & 17,50 \\
\hline Buğday, \% & 7,50 & 10,00 & 12,50 & 15,00 \\
\hline Soya yağı, \% & 0,71 & 3,07 & 5,20 & 5,58 \\
\hline Tavuk unu, \% & 1,50 & 2,00 & 3,00 & 3,50 \\
\hline Mısır glüteni, \% & 8,41 & 6,63 & 1,50 & - \\
\hline Et kemik unu, \% & 1,50 & 2,00 & 2,44 & 2,64 \\
\hline DCP, \% & 1,46 & 1,00 & 0,72 & 0,48 \\
\hline Metionin, \% & 0,24 & 0,23 & 0,23 & 0,24 \\
\hline Vitamin mineral premiksi, \% & 0,50 & 0,50 & 0,50 & 0,50 \\
\hline Tuz, \% & 0,21 & - & 0,18 & 0,17 \\
\hline Sodyum bikarbonat, \% & 0,15 & 0,15 & 0,15 & 0,15 \\
\hline Mermer tozu, \% & 0,33 & 0,16 & - & - \\
\hline Toksin bağlayıcı, \% & 0,10 & 0,10 & 0,10 & 0,10 \\
\hline Cholin clorid, \% & 0,09 & 0,09 & 0,09 & 0,09 \\
\hline Threonin, \% & 0,08 & 0,08 & 0,07 & 0,07 \\
\hline Lysin, \% & 0,32 & 0,27 & 0,10 & 0,04 \\
\hline TOPLAM & 100,00 & 100,00 & 100,00 & 100,00 \\
\hline \multicolumn{5}{|c|}{ Hesaplanan değerler } \\
\hline Kuru madde, \% & 89,72 & 89,74 & 89,81 & 89,82 \\
\hline Ham protein, \% & 25,83 & 24,30 & 22,40 & 22,17 \\
\hline Metabolik enerji & $3.025,00$ & $3.200,00$ & $3.300,00$ & $3.325,00$ \\
\hline Ham yağ,\% & 7,90 & 9,31 & 11,30 & 11,87 \\
\hline Ham selüloz, \% & 3,45 & 3,30 & 3,32 & 3,38 \\
\hline Kalsiyum, \% & 1,00 & 0,90 & 0,86 & 0,82 \\
\hline Fosfor, \% & 0,50 & 0,45 & 0,43 & 0,41 \\
\hline
\end{tabular}

Diyette kilogram başına; 10.000 IU A vitamini, $12 \mathrm{mg}$ E vit., $2000 \mathrm{IU}$ D vit., $30 \mathrm{mg}$ niasin, $10 \mathrm{mg}$ D-patotenik asit, 3.61 $\mathrm{mg}$ riboflavin, $3.52 \mathrm{mg}$ pridoxin, $2.41 \mathrm{mg}$ tiamin, $1.39 \mathrm{mg}$ folik asit, $0.16 \mathrm{mg}$ biotin ve $0.03 \mathrm{mg}$ B vit., $59 \mathrm{mg}$ manganez,

$41 \mathrm{mg}$ çinko, $1281 \mathrm{mg}$ demir, $7.9 \mathrm{mg}$ bakır, $0.31 \mathrm{mg}$ iodin ve $0.22 \mathrm{mg}$ selenyum.

İstatiksel analizler; elde edilen verilerin varyans analizi Genel Linear Model prosedürü ile verielerin önem kontrolleri SPSS SPSS 20.0 paket programı kullanılarak yapılmıştır. Gruplar arasınadaki farklılıklar Duncan çoklu karşılaştırma testi ile belirlenmiştir.

\section{ARAŞTIRMA BULGULARI VE TARTIŞMA}

Araştırma sonucun da elde edilen değerler çizelge 2 ve 3 'de sunulmuştur. 
Alınteri Journal of Agriculture Sciences. 2018, 33(1): 1-6

Alınteri Zirai Bilimler Dergisi

Çizelge 2. Canlı Ağırlık ve Yemden Yararlanma Oranına Ait Değerler

\begin{tabular}{lcc}
\hline \multirow{2}{*}{ Gruplar } & \multicolumn{2}{c}{$\mathbf{1 - 4 5}$ gün } \\
\cline { 2 - 3 } & Canlı Ağırlık (g) & Yemden Yararlanma Oranı \\
\hline Grup K & $1964^{\mathrm{c}} \pm 211$ & $1,78 \pm 0.34$ \\
\hline Grup K+S & $1548^{\mathrm{a}} \pm 325$ & $1,84 \pm 0.26$ \\
\hline Grup T & $1888^{\mathrm{bc}} \pm 302$ & $1,96 \pm 0.65$ \\
\hline Grup T+S & $162^{\mathrm{ab}} \pm 223$ & $1,91 \pm 0.31$ \\
\hline Grup H & $1749^{\mathrm{abc}} \pm 302$ & $1,87 \pm 0.29$ \\
\hline Grup H+S & $1614^{\mathrm{a}} \pm 249$ & $1,98 \pm 0.33$ \\
\hline $\mathbf{p}$ & $*$ & ÖS \\
\hline (Ortalama. \pm Standart hata).ÖS: Önemsiz ve a, b, c: Aynı sütunda farklı harfle gösterilen ortalamalar arası fark önemlidir \\
(p<0.05).
\end{tabular}

Çizelge 3. Baş, Karaciğer ve Bağırsak ağırlığına ait değerler (Ortalama.土Standart hata).

\begin{tabular}{lccc}
\hline \multirow{2}{*}{ Gruplar } & \multicolumn{3}{c}{$\mathbf{1 - 4 5}$ gün } \\
\cline { 2 - 4 } & Baş ağırlı̆̆ı $(\mathbf{g})$ & Karaciğer ağırlı̆̆ı $(\mathbf{g})$ & Bağırsak ağırlıkları $(\mathbf{g})$ \\
\hline Grup K & $48 \pm 4.83$ & $239^{\mathrm{b}} \pm 41.5$ & $148,77^{\mathrm{b}} \pm 24.55$ \\
\hline Grup K+S & $51 \pm 6.59$ & $180,5^{\mathrm{a}} \pm 38$ & $110^{\mathrm{a}} \pm 17.96$ \\
\hline Grup T & $50,5 \pm 5.99$ & $239^{\mathrm{b}} \pm 40.7$ & $157,19^{\mathrm{b}} \pm 23.67$ \\
\hline Grup T+S & $50,5 \pm 3.69$ & $184^{\mathrm{a}} \pm 29.1$ & $111,3^{\mathrm{a}} \pm 13.14$ \\
\hline Grup H & $52 \pm 5.37$ & $211^{\mathrm{ab}} \pm 29.5$ & $134,1^{\mathrm{ab}} \pm 13.51$ \\
\hline Grup H+S & $49,4 \pm 9.8$ & $181,3^{\mathrm{a}} \pm 28.1$ & $110.25^{\mathrm{a}} \pm 13.12$ \\
\hline p & ÖS & $*$ & $*$ \\
\hline
\end{tabular}

ÖS: Önemsiz ve a, b: Aynı sütunda farklı harfle gösterilen ortalamalar arası fark önemlidir $(\mathrm{p}<0.05)$.

Yapılan istatiksel analiz sonuçlarına bakıldığında Deneme sonu canlı ağırlık, karaciğer ve bağırsak ağırlıklarına ait değerler için $\mathrm{p}<0.05$ anlamlılık düzeyinde ortalamalar arasındaki fark istatistiksel olarak anlamlı bulunmuştur. Yemden yararlanma oranları ile baş ağırlıklarına ait değerlerde istatistiksel öneme sahip herhangi bir fark olmamıştır. Çizelge 2'ye bakıldığında Deneme sonu canlı ağırlıklarında Grup K, Grup T ve Grup H' nin değerleri bezer olurken Grup K'nın sicaklık stresi uygulanan tüm gruplarla (Grup K+S, Grup T+S, Grup H+S) arasındaki fark önemli olmuştur $(\mathrm{p}<0.05)$. Ayrıca Grup T ile Grup $\mathrm{K}+\mathrm{S}$ ve Grup $\mathrm{H}+\mathrm{S}$ arasındaki farkta önemli olmuştur $(\mathrm{p}<$ 0.05). Çizelge 3 'teki karaciğer ve bağırsak ağırlıklarında da Grup K, Grup T ve Grup H' nin değerleri arasında önemli bir fark olmazken, Grup K ve Grup T ile sicaklık stresi uygulanan tüm gruplar (Grup $\mathrm{K}+\mathrm{S}, \mathrm{Grup} \mathrm{T}+\mathrm{S}$, Grup $\mathrm{H}+\mathrm{S})$ arasındaki fark önemli olmuştur $(\mathrm{p}<0.05)$.

Yem katkı maddesi olarak kullanılacak maddelerin hem yemlerde hem de elde edilen ürünlerde saptanabilir olmaları, bu maddelerin insan sağlı̆̆ına olan etkilerinin denetlemesinde önemlidir (Eren, 2001). Hayvan beslemede kullanılacak yem katkı maddelerinin insan sağlı̆̆ üzerine olumsuz etki oluşturmayan, hayvansal ürün verimini ve kalitesini artıran (Erkek, 1991 ) bunun yanı sıra sıcaklık stresinin olumsuz etkilerini de yok edebilecek, doğal bitki ve bitki ekstraktları'nın yem katkısı olarak kullanımı önem kazanmıştır.

$\mathrm{Bu}$ doğrultuda kanatlılarda yapılan bir çalışmada gruplara sıcaklık stresi ve bitki ekstraktı uygulaması canlı ağırlık artışı ve yem tüketimini etkilemezken, yemden yararlanma oranını iyileştirdiği bulunmuştur (Çiftci, 2013). Başka bir çalışmada da broiler yemine katılan Hypericum perforatum tozunun büyüme performansına olumlu bir etkisinin olmadığı ve canlı ağırlığ da azalttığı bildirilmiştir (Landy et al., 2012). Yine yapılan başka bir çalışmada bitki ekstraktı içeren rasyonla beslenen broilerde yem tüketimi, bağırsak uzunluğunu ve ağırlığı ile bazı organ ağırlıkları etkilemezken, canlı ağırlığı azaltığı ( Hosseinzadeh, 2014) gibi fitojenik ekstrakt katkılı yemle beslenen broilerin de karaciğer ağırlığının değişmediği (Jamroz, 2003) bildirilmiştir. Yine rat (Tahtamouni et al., 2016) ve tavşanlar (Choi, 2010) da T. officinale L. katkısının böbrek, karaciğer ve vücut ağırlığına etki etmediği bulunmuştur. Yapılan çalışma da sıcaklık stresi uygulanan şartlarda elde edilen veriler diğer çalışmalarla benzer olmuştur. Ancak ortaya çıkan olumsuz etkilerin sıcaklık stresi sonucun da serbest radikallerin artışıyla oksidatif stresin oluşmasına bunun da vücut ağırlığının, yem tüketiminin ve yemden yararlanma oranının azalmasına (Bartlett and Smith, 2003; Mashaly, et al., 2004; Gavazza, 2006) sebep olduğundan dolayı gerçekleştiği düşünülüyor. Yapılan literatür taramasında Hypericum scabrum L. ve Taraxacum officinale L. eksraktlarının antioksidan özellikleri ile biyokimyasal parametrelerin incelendiği çalışmalara erişilebilmektedir (Dönmez ve 
Keskin, 2007; Apaydın Yıldırım, 2016). Fakat sıcaklık stresi altında veya normal şartlarda broilerde performans değerleri üzerine Hypericum scabrum L. ve Taraxacum officinale L. eksraktlarının etkisinin incelendiği herhangi bir çalışmaya rastlanamadı.

\section{SONUÇ VE ÖNERILER}

Sonuç olarak, broilerlerin sıcaklık stresine yaşamlarının sadece bir döneminde maruz kalsalar dahi sıcaklık stresinin olumsuz etkilerinin ortaya çıkması için yeterli olduğu, ayrıca Hypericum scabrum L. ve Taraxacum officinale $L$. bitki eksraktlarının sıcaklık stresine etki etmediği gibi normal şartlar altında da broilerlerin performans değerlerine olumlu etkisinin olmadığı ortaya çıkmıştır. Hayvan beslemede yem katkısı olarak kullanılan bitki ve bitki ekstraktlarının hayvanlara ve hayvansal ürünlere olan etkisi, bitkilerin özelliklerine, hasat dönemine, kullanılan kısımlarına ve işleme tekniğine bağlı olarak değişmektedir (Muhl ve Liebert, 2007; Lee vd., 2003). Bu faktörler göz önüne alındığında karma yemlere katılan bitki ve bitki ekstratlarının etkilerinin tam olarak belirlenmesinin oldukça güç olduğu ve çok sayıda çalışma yapılması gerektirdiği görülmektedir. Yapılan çalışmada elde edilen verilerin de bu anlamda kaynak teşkil edebileceği düşünülmektedir.

\section{KAYNAKLAR}

Alarslan, Ö.F, 2000. Kümes Hayvanlarının Beslenmesi. A.Ü. Ziraat Fakültesi Zootekni Bölümü.Ders Notu, Ankara, 188 s.

Amin Mir, M., Sawhney, S.S., and Jassal, M.S., 2016. Antimicrobial Activity of Various Extracts of Taraxacum officinale. J Microb Biochem Technol. 8:3. http://dx.doi.org/10.4172/1948-5948.1000287

Apaydın Yıldırım, B., 2016. Sıcaklık Stresi Oluşturulan Broylerlerde Yeme İlave Edilen Taraxacum officinale L. ve Hypericum scabrum L. Bitki Ekstraktlarının Bazı Biyokimyasal Parametreler Üzerine Etkileri. Atatürk Üniv. Ziraat Fak. Derg., 47 (1): 65-70. ISSN: 1300-9036.

Bartlett, J. R., and Smith, M.O., 2003. Effects of different levels of zinc on the performanceand immunocompetence of broilers under heat stress. Poult. Sci., 82: 1580-1588.

Baytop, T., 1997. Türkçe Bitki Adları Sözlüğü. 2. Baskı. Türk Tarih Kurumu Basımevi, Ankara.

Bisset, N.G., Phillipson, J.D., Czygan, F.C., Frohne, D., Höltzel, D., Nagell, A., Pfande,r H.J., Willuhn, G., Buff, W. (Eds.)., 1994. Herbal Drugs and Phytopharmaceuticals: A Handbook for Practice on a Scientific Basis, CRC Press, Boca Raton, Ann Arbor, London, Tokyo. Pp: 486-489.

Choi, U.K., Lee, O.H., Yim, J.H., 2010. Hypolipidemic and antioxidant effects of dandelion(Taraxacum officinale) root and leaf on cholesterol-fed rabbits. Int J Mol Sci., 11(1): 67-78.

Christie, P.J., Alfenito, M.R., Walbot, V., 1994. Impact of low-temperature stress on general phenylpropanoid and anthocyanin pathways: enhancement of transcript abundance and anthocyanin pigmentation in maize seedlings. Planta, 194: 541549.

Çınar, A., Belge, F., Dönmez, N., Taş, A., Selçuk, M., Tatar, M., 2006. Effects of Stress Produced by Adrenocorticotropin (ACTH) on ECG and some Blood Parameters inVitamin C Treated and Non-treated Chickens. Veterinarski Arhiv. 76 (3): $227-235$.

Çiftçi, M., Ertaş, O.N., Güler, T., 2005. Effects of vitamin E and vitamin C dietary supplementation on egg production and egg quality of laying hens exposed to a chronic heat stress. Revue Med Vet, 156: 107-111.

Çiftci, M., Şimşek, Ü.G., Azman, M.A., Çerçi, H.İ., Tonbak, F., 2013. The Effects of Dietary Rosemary (Rosmarinus officinalis L.) Oil Supplementation on Performance, Carcass Traits and Some Blood Parameters of Japanese Quail Under Heat Stressed Condition. Kafkas Univ Vet Fak Derg., 19 (4): 595-599. DOI: 10.9775/kvfd.2012.8474.

Daneshyar, M., Kermanshahi, H., Golian, A., 2009. Changes of biochemical parameters andenzyme activities in broiler chickens withcold-induced ascites. Poult Sci, 88: 106-110.

Davis, P.H., 1965. Flora of Turkey and The East Aegea Islands, Edinburg, The University Press.

Donkoh, A., 1989. Ambient temperature: A factor affecting performance and physiologicalresponse of broiler chickens. Int $\mathbf{J}$ Biometeorol, 33: 259-265.

Dönmez, N., Keskin, E., 2007. Isı stresi oluşturulan broylerlerde antibakteriyel etkili bitki eksraktının (Herbromix) bazı antioksidanlar ve Kan parametreleri üzerine etkisi. Vet.Bil. Derg., 23: 3-4, 51-55.

Dönmez, H.H., Yörük, M., Çınar, A., Dönmez, N., 2007. Effects of Vitamin C on ANAE Positivity and Blood Cells in ACTH Induced Stress in Chicken. Ind. Vet. J. in press.

Ebrahimzadeh, M., Nabavi, S., Nabavi, S., Ahangar, N., 2013 Anticonvulsant activity of Hypericum scabrum L.; possible mechanism involved. Eur Rev Med Pharmacol Sci,17: 2141-2144.

Eren, M., 2001. Verim Artırıcılarda Son Gelişmeler. In: Yavuz HM (ed). Çiflik Hayvanlarının Beslenmesinde Temel Prensipler ve Karma Yem Ürertiminde Bazı Bilimsel Yaklaşımlar, I. baskı. İstanbul, Farmavet İlaç Sanayi ve Ticaret AŞ, 361382.

Erkek, R., 1991. Yem katkı maddelerinin gelişimi ve kullanımı. Yem Sanayi Derg., 73: 19-23.

Ertaş, Ö.S., Aktaş, H.F., Haznedaroğlu, M.Z., 2005. Analysis of sodium and potassium levels in Taraxacum officinale by flame emission photometry Acta Pharmaceutica Turcica,47: 127-130.

Gavazza, M., and Catala, A., 2006. The effect of $\alpha$-tocopherol on lipid peroxidation of microsomes and mitochondria from rat testis. Prostaglandins, Leukotrienes and Essential Fatty Acids, 74: 247-254.

Ho, C., Choi, E.J., Yoo, G.S., Kim, K.M., Ryu, S.Y., 1998. Desacetylmatricarin, an anti-allergiccomponent from Taraxacum platycarpum. Planta Medica, 64: 577-578.

Hosseinzadeh*1, Z., and Moghaddam², G., 2014. Effects of Tarragon Powders' DifferentLevels (Artemisia Dracunculus) on general Performance and Anetometric Properties of Digestive System of male Broiler chickens. International journal of Advanced Biological and Biomedical Research, 2(5): 1599-1605. 
Hu, C., Kitts, D.D., 2005. Dandelion (Taraxacum officinale) flower extract suppresses bothreactive oxygen species and nitric oxide and prevents lipid oxidation in vitro Phytomedicine, 12: 588-597.

Jamroz, D., Orda, J., Kamel, C., Wiliczkiewic, A., Wertelecki, T., and Skorupińska, J., 2003. The influence of phytogenic extracts on performance, nutrient digestibility carcass characteristics, and gut microbial status in broiler chickens. Journal of Anima and Feed Sciences, 12: 583-596.

Karsl1, M.A., Dönmez, H.H., 2007. Effects of plant extract on growth performance and villi of the small bowel in heat stressed broiler. Ataturk Univ Vet Bil Derg., 2: 143-148.

Keskin, C., 2015. Antioxidant, anticancer and anticholinesterase activities of flower, fruit and seed extracts of Hypericum amblysepalum HOCHST. Asian Pac J Cancer Prev, 16: 2763-2769.

Kim, H.M., Shin, H.Y., Lim, K.H., Ryu, S.T., Shin, T.Y., Chae, H.J., Kim, H.R., Lyu, Y.S., An, N.H., Lim, K.S., 2000. Taraxacum officinale inhibits tumor necrosis factor alpha production from rat asterocytes Immunopharmacology and Immunotoxicology, 22:519-530.

Koç, H., 2002. Doğrudan, doğadan bitkilerle sağlıklı yaşama. Gaziosmanpaşa Üniversitesi Ziraat Fakültesi Tarla Bitkileri Bölüm Yayını. Tokat, Ümit Ofset.

Kurbanov, M. K., Mutayev, M. M., 1993. Contents of biologically active substances in Hypericum scabrum L. growing in different regions of Tajikistan Rastit Resur, 29(1):40-43.

Landy, N., Ghalamkari, G. H., and Toghyani, M., 2012. Evaluation of St John's Wort (Hypericum perforatum L.) as an antibiotic growth promoter substitution on performance, carcass characteristics, some of the immune responses, and serum biochemical parameters of broiler chicks. J. Med Plants Res., 6: 510-515.

Lee, K.W., Everts, H., Kappert, H.J., Freher, M., Losa, R., Beynen, A.C., 2003. Effects of dietary essantial oil components on growth performance, digestive enzymes and lipit metabolism in female broiler chickens. Brit Poult Sci., 44: 450-457.

Mashaly, M.M., Hendricks, G.L.3rd, Kalama, M.A., Gehad, A.E., Abbas, A.O., and Patterson, P.H., 2004. Effect of heat stress on production parameters and immune responses of commercial laying hens. Poult. Sci., 83: 889-894.

Muhl, A., Liebert, F., 2007. Growth nutrient utilization and threonine requirement of growing chicken fed threonine limiting diets with commercial blends of phytogenic feed additives. J Poult Sci., 44: 297-304.

Önal, S., Timur, S., Okutucu, B., Zihnioğlu, F., 2005. Inhibition of $\alpha$-glucosidase by aqueous extract of some potent antidiabetic medicinal herbs Preparative Biochemistry \& Biotechnology, 35: 29-36.

Pirbalouti, A.G., Fatahi-Vanani, M., Craker, L., and Shirmardi, H., 2014. Chemical composition and bioactivity of essential oils of Hypericum helianthemoides, Hypericum perforatum and Hypericum scabrum. Pharm Biol, 52(2): 175-181. ISSN 1388-0209 print/ISSN 1744-5116 online.

Puvaldopirod, S., Thaxton, J.P., 2000. Model of physiological stres in chickens 2. Dosimetry of Adrenocorticotropin. Poult. Sci. 80, 1190- 1200 .

Sweeney B., Vora M., Ulbricht C., Basch E., 2005. Evidence-based systematic review of dandelion (Taraxacum officinale)by natural standard research collaboration Journal of Herbal Pharmacotherapy, 5: 79-93.

Şahin, K., Smith, M.O., Önderci, M., Şahin, N., Gürsu, M.F., Küçük, O., 2005. Supplementation of zinc from organic or inorganic source improves performance and antioxidant status of heat-distressed quail. Poult Sci., 84: 882-887.

Tahtamouni, L.H., Al-Khateeb, R.A., Abdellatif,R.N., Al-Mazaydeh, Z.A., Yasin,S.R., Al-Gharabli, S., Elkarmi, A.Z., 2016. Anti-spermatogenic activities of Taraxacum officinale whole plant and leaves aqueous extracts. Veterinary Research Forum, 7 (2): $89-97$.

Unal, E.L., Mavi, A., Kara, A.A., Cakir, A., Şengül, M., Yildirim, A., 2008. Antimicrobial and antioxidant activities of some plants used as remedies in Turkish traditional medicine. Pharm Biol., 46: 207-224.

Yun, S.O., Cho, H.R., Choi, H.S., 2002. Anticoagulant from Taraxacum platycarpum.Bioscience, Biotechnology and Biochemistry, 66: 1859-1864. 